\title{
Frameworks of Team Processes in Sport: A Critical Review with Implications for Practitioners
}

\author{
Jamie Collins", Natalie Durand-Bush \\ School of Human Kinetics, University of Ottawa, Canada
}

Copyright (C) 2015 by authors, all rights reserved. Authors agree that this article remains permanently open access under the terms of the Creative Commons Attribution License 4.0 International License

\begin{abstract}
Researchers have directly or indirectly examined team processes that contribute to team functioning and effectiveness in sport. However, in doing so, they have typically focused on team cohesion, they have not consistently addressed the theoretical/conceptual frameworks underpinning their work, nor have they comprehensively derived implications for practice. Furthermore, existing meta-analyses and reviews on cohesion and team building address results of empirical studies and do not evaluate the specific theoretical/conceptual frameworks used to guide these studies. Consequently, the purpose of this study was to critically review theoretical/conceptual frameworks directly or indirectly addressing team processes in sport and derive implications for professional practice. Seven frameworks used to guide research and/or practice in sport were identified for inclusion in this study. Three frameworks were borrowed from general psychology and the other four stemmed from sport psychology. These frameworks targeted a variety of specific team processes and six different outcomes, the most common of which was cohesion. Specific team processes were categorized under broader team processes, the latter of which were linked to one of ten general themes. The theme pertaining to roles/norms was the most prevalent one as it was addressed in six out of the seven frameworks. Conversely, one of the least prevalent general themes related to goals; it was only discussed in two of the seven frameworks. Implications for practitioners aiming to optimize team processes in sport and recommendations for future research are presented.
\end{abstract}

Keywords Team Processes, Team Building, Team Dynamics, Theoretical Frameworks, Sport, Practitioners

\section{Introduction}

Words such as 'teamwork', 'cohesion', 'chemistry', and 'unity' have been used in association with highly successful teams. Indeed, several scholars have directly or indirectly shed light on team processes that contribute to team functioning and effectiveness in sport. Moreover, several frameworks have been proposed to guide research and practice in this context. However, research has been fragmented [1], focusing on few rather than exhaustive team processes and prioritizing team cohesion. Furthermore, attempts to transfer knowledge have been limited. In fact, few concrete guidelines have been proposed in the literature to help practitioners nurture team processes and effectiveness within different sports [2,3]. Consequently, it is challenging to determine how empirical knowledge can be used in practice.

The overall purpose of this study was to critically examine frameworks of team processes in sport and draw implications for practitioners. The specific objectives were to (a) identify theoretical/conceptual frameworks in the literature addressing one or more team processes relevant for sport, (b) identify the specific team processes directly or indirectly targeted in these frameworks along with outcomes, (c) determine broader team processes and general themes and compare them across frameworks, (d) evaluate the frameworks based on their strengths and limitations, (e) report or infer implications for practice, and (f) make recommendations for future research. As noted by Goodger and colleagues [4], reviews such as this are valuable as they "consolidate findings and identify the known and the unknown" (p. 129). Although several constructs have been presented in existing frameworks, certain underlying team processes and ways they may be applied in practice remain ambiguous or "unknown". Intended outcomes are also sometimes vague and ill-defined. Moreover, while meta-analyses and reviews on cohesion and team building have been conducted in the past [e.g., 5,6,7,8], they pertain to concrete results of empirical studies and do not evaluate the specific theoretical/conceptual frameworks used to guide these studies.

\section{Review Method}

We selected each framework based on a review of scientific articles related to team processes found in several electronic databases (e.g., SPORTDiscus, Google Scholar, ERIC) as well as key group dynamics texts [e.g., 9,10]. A number of key words were used when searching for frameworks, for example, group/team dynamics, group/ team processes, cohesion, team building, team effectiveness, 
team functioning, teamwork, team chemistry, and team unity. Additionally, specific team processes were also searched, such as communication, interaction, and coordination. Only theoretical or conceptual frameworks used to guide research and/or practice in sport (i.e., scientific articles, textbooks) were included in this study. As such, the most recent conceptual framework for teamwork and team effectiveness put forth by McEwan and Beauchamp [1] was not included as it has yet to be used in sport psychology research or practice. This framework will, however, be addressed in the discussion section.

Our review and analysis consisted of seven steps: (a) we first searched electronic databases; (b) we then read the literature to identify frameworks used to guide research and/or practice in sport; (c) after selecting the seven frameworks, we reviewed in more depth the literature pertaining to these frameworks; (d) next, we performed a content analysis using the literature describing the frameworks in order to identify the specific team processes that were explicitly reported [e.g., set team goals, 11] or that could be implicitly inferred based on definitions and descriptions of constructs [e.g., identify actual and required resources, 12] within each framework; (e) we subsequently conducted a second level of analysis to extract broader team processes based on the list of specific team processes that we generated in the previous step; (f) we then engaged in a third level of analysis to identify general themes under which we could regroup the broader team processes; and (g) we compared specific team processes, broader team processes, and general themes at all levels of analyses and summarized the results in two comparative tables.

Seven frameworks used to guide research and/or practice in sport were identified for inclusion in this study. These frameworks targeted a variety of specific team processes and anywhere from two to twelve broader team processes and one to three main outcomes. Table 1 provides a summary of these processes and outcomes. In the first column, the seven frameworks are identified (e.g., framework for examining the correlates of cohesion). The specific or 'raw' team processes addressed in each of the frameworks are then presented in column 2 based on the authors' descriptions [e.g., identify individual team members' orientation/motivation for being part of the team, address individual differences, and nurture member satisfaction (personal factors)]. From the specific team processes, broader team processes were then inductively identified in column 3 in an effort to group specific processes in a way that would facilitate comparison (e.g., identify/respect personal characteristics). Finally, the outcomes targeted in each framework are presented in column 4 . With regards to Table 2, the broader team processes presented in the third column of Table 1 were further inductively categorized under ten general themes (e.g., personal characteristics), which are presented along the top of Table 2. The 'X's indicate which particular general theme were addressed in the seven frameworks. As such, Table 2 presents the most and least common general themes addressed across frameworks (as seen in the totals at the bottom of Table 2). It also highlights the most comprehensive frameworks (i.e., frameworks targeting the most general themes, as seen in the totals in the last column of Table 2).

\section{Review of Frameworks}

In our review of the literature, we examined key definitions and situated the concept of "team processes" in sport. Prior to the 1980 's, sport cohesion research lacked a sound theoretical and/or conceptual foundation [13,14]; cohesion was defined and measured differently in nearly every study [15]. In response to the conceptual obscurity, Carron [14] proposed an operational definition of cohesion in which it was characterized as being multidimensional, dynamic, and instrumental. Later, an affective dimension was added to reflect the social relationships that develop among team members [16]. Thus, cohesion in sport was eventually defined as a "dynamic process that is reflected in the tendency for a group to stick together and remain united in the pursuit of its instrumental objectives and/or for the satisfaction of member affective needs" [16, p. 213]. This definition now forms the basis of nearly all of the sport cohesion research $[9,17]$.

Of interest, the specific "dynamic process" to which Carron and colleagues [16] alluded in their definition has not been examined in great depth. Consequently, there has been a call for exploring team processes that contribute to enhanced cohesion and performance in sport in order to understand why such relationships exist $[13,18,19]$. In the general group dynamics literature, processes refer to "acts that convert inputs to outcomes through cognitive, verbal, and behavioral activities directed toward... [achieving] collective goals" [20, p. 357]. In the sport psychology literature, processes are defined as the "intrapersonal and interpersonal actions by which individuals transform their resources into performance" [21, p. 3]. They "represent the dynamic interactions that are a fundamental, integral characteristic of group involvement" [9, p. 263]. Considering these definitions, it can be argued that the dynamic processes in which members of a team engage are key to achieving different outcomes. Such team processes were the focus of our review and analysis and are discussed in relation to each framework next.

\subsection{Frameworks from General Psychology}

\subsubsection{Tuckman's [22] Theory of Group Development}

Tuckman's [22] theory was included in this review as it is one of the first to highlight different processes involved in group development. This scholar's framework is often cited in both the general and sport group dynamics literature because it provides support for the notions that task and social cohesion change over the course of a team's formation and development [23].

Tuckman [22] suggested that groups or teams evolve through different linear stages, which he summarized as 
forming, storming, norming, and performing; a fifth stage, adjourning, was later added to account for team termination [24]. Twelve broader team processes related to these stages were identified (i.e., identify tasks; identify context; establish relationships; identify organizational standards; identify/challenge personal characteristics; identify/ challenge team characteristics; communicate/respect personal characteristics; communicate/respect team characteristics; establish roles and norms; adapt/fulfill roles; converge members' attention on tasks; terminate relationships), which impact the two main outcomes of cohesion and performance (see Table 1). In the forming stage, team members orient themselves to one another, the task, and the context, and test the boundaries for interpersonal task behaviours. During this stage, relationships with leaders and other team members are established, and members familiarize themselves with organizational standards (e.g., norms). In the storming stage, teams undergo a period of interpersonal conflict (e.g., hostility towards team members stemming from expressing individuality) and members polarize. During norming, opposition subsides, as team members begin to accept individual differences and idiosyncrasies. Roles and norms are established, team members are able to communicate personal opinions, and 'in-group' feelings start to develop. This in turn leads to successful task execution during the performing stage wherein members develop functional role relatedness. Team members adapt and fulfill their roles and team energy is channeled towards task performance [22,25]. In the adjourning stage, the team prepares for dissolution and relationships are terminated [24]. Essentially, teams must develop the aforementioned processes and unite in order to advance to the next stage of development, otherwise they could prematurely disband. According to Tuckman [22], the sequence of stages remains the same for all teams, however, the duration of each stage varies across teams.

Although Tuckman's [22] linear stage model has several merits, it fails to account for the extent to which cohesion is dynamic and for the shifts that occur in interpersonal relationships over the course of a team's existence. Rather, cohesion should be viewed as being in a constant state of flux characterized by peaks and valleys [2]. Moreover, teams may revisit some of the stages at different times in their development or may completely skip a stage [26]. For example, if a soccer team returns for a second season with only a few line changes, they may not spend time in the forming stage and may instead skip directly to storming [9]. That said, it should be noted that when Tuckman [22] developed his framework, cohesion was not yet defined as a dynamic and multidimensional process but rather as forces holding a group together [9]. Additional limitations of Tuckman's [22] framework are consistent with most stage theories. Specifically, it can be criticized for: (a) the blurred separation between stages [26]; (b) its failure to account for the psychological mechanisms that help a team move from one stage to another; and (c) its disregard for the external environment [14].

Despite these criticisms, there are several valuable implications for practitioners. As previously stated, Tuckman [22] suggested that team processes evolve over the course of team formation and development. Thus, knowledge of the five stages is useful as it can help practitioners: (a) anticipate when and what types of problems might arise over the course of team development, (b) normalize issues relating to team dynamics as a natural and essential part of becoming a cohesive team, and (c) tailor interventions to the specific needs of teams at specific times. For example, practitioners with knowledge of the forming stage would expect to see members engaging in 'testing' or exploration to determine the limits of behavior [22]. Thus, when certain behaviours become evident, it would signal an appropriate time to address norms and expectations, for example, by having teams create and sign a code of conduct. By staying mindful of the five stages, it can allow practitioners to periodize their work with teams [27] so as to ensure that they are addressing key processes at the right point in their development, thus helping members progress towards performing at the right time.

\subsubsection{Steiner's [12] Theory of Group Productivity}

Steiner's [12] theory of group productivity was included in this review because of its unique focus on productivity and resources, which are not explicitly addressed in the other frameworks. In general, Steiner [12] referred to productivity as what individuals or teams accomplish. We identified four broader team processes (i.e., identify personal characteristics; identify team characteristics; coordinate actions; establish roles) that contribute to the main outcome of productivity (i.e., effectiveness and efficiency of task achievement) in this framework (see Table 1).

According to Steiner [12], a team's actual productivity is equal to its potential productivity, defined as the amount of relevant resources available (e.g., knowledge, attributes, and skills of team members) minus the losses due to faulty team processes. These faulty team process losses, which stem from the actions of team members, can be caused by either a loss of individual productivity (reduced motivation) and/or poor coordination of members [9]. The potential for productivity may increase with team size due to the additional resources available. However, eventually all of the necessary resources are present, at which point additional members only lead to a greater likelihood of team process losses [9]. Thus, it can be inferred that to maximize productivity, the following specific team processes are important: (a) identify the actual and required resources to achieve a task (e.g., determine the optimal number of members on a team), (b) coordinate team members' actions, and (c) motivate team members by clarifying their role in task achievement. Although not developed specifically for sport, Steiner's [12] theory has been viewed as applicable in this context due to its performance orientation and has guided much of the research on group size and social loafing in sport [28]. 
Interestingly, poor coordination of members has been proposed as the primary cause of reduced individual productivity in groups $[29,30]$. However, Eccles [31] noted that studies have not particularly explored this relationship and mainly focused on reduced individual productivity such as motivation and social loafing. As such, coordination losses and the coordination of tasks have gone unexplored [32]. The reason for disregarding coordination losses in sport teams is unclear but there are possible explanations. It may be due to the social rather than cognitive perspective typically adopted when studying sport teams $[32,33]$ and/or the inherent difficulty in studying team coordination, in part due to an absence of measurement instruments [32]. To date, scholars have only been able to speculate that decreasing performance with increasing team size has been a result of poor coordination [34].

Table 1. Summary of processes and outcomes targeted in theoretical/conceptual frameworks of team processes in sport

\begin{tabular}{|c|c|c|c|c|}
\hline Framework & & Specific Team Processes & Broader Team Processes & Outcomes \\
\hline \multicolumn{5}{|c|}{ Emerged from General Psychology } \\
\hline \multirow{5}{*}{$\begin{array}{l}\text { 1. Theory of group } \\
\text { development }[22,24]\end{array}$} & a) & $\begin{array}{l}\text { Orient members to the task; create ground rules; test } \\
\text { boundaries for interpersonal task behaviours; establish } \\
\text { relationship with leaders and each member; identify } \\
\text { organizational standards (forming stage) }\end{array}$ & $\begin{array}{c}\text { Identify tasks } \\
\text { Identify context } \\
\text { Establish relationships } \\
\text { Establish norms }\end{array}$ & \multirow{5}{*}{$\begin{array}{l}\text { Cohesion } \\
\text { Performance }\end{array}$} \\
\hline & b) & $\begin{array}{l}\text { Confront interpersonal issues; confront emotional } \\
\text { responses to tasks (storming stage) }\end{array}$ & $\begin{array}{l}\text { Identify/challenge personal characteristics } \\
\text { Identify/challenge team characteristics }\end{array}$ & \\
\hline & c) & $\begin{array}{l}\text { Promote acceptance of individual } \\
\text { differences/idiosyncrasies; facilitate expression of } \\
\text { personal opinions; establish roles and norms; prioritize } \\
\text { the team as an entity and strengthen 'in-group' feeling } \\
\text { (norming stage) }\end{array}$ & $\begin{array}{c}\text { Communicate/respect personal } \\
\text { characteristics } \\
\text { Communicate/respect team characteristics } \\
\text { Establish roles and norms }\end{array}$ & \\
\hline & d) & $\begin{array}{l}\text { Develop functional role relatedness; solve problems as } \\
\text { members adapt and fulfill their roles; channel energy } \\
\text { into tasks (performing stage) }\end{array}$ & $\begin{array}{c}\text { Adapt/fulfill roles } \\
\text { Converge members' attention on tasks }\end{array}$ & \\
\hline & e) & Terminate relationships (adjourning stage) & Terminate relationships & \\
\hline \multirow{3}{*}{$\begin{array}{l}\text { 2. Theory of group } \\
\text { productivity [12] }\end{array}$} & a) & $\begin{array}{l}\text { Identify actual and required resources (e.g., } \\
\text { knowledge, attributes, skills of team members) }\end{array}$ & $\begin{array}{l}\text { Identify personal characteristics } \\
\text { Identify team characteristics }\end{array}$ & \multirow{3}{*}{ Productivity } \\
\hline & b) & Coordinate team members' actions & Coordinate actions & \\
\hline & c) & $\begin{array}{l}\text { Motivate team members by clarifying their role } \\
\text { in/contribution to task achievement }\end{array}$ & Establish roles & \\
\hline \multirow{3}{*}{$\begin{array}{l}\text { 3. Personality-based } \\
\text { preference } \\
\text { framework for team } \\
\text { communication [36] }\end{array}$} & a) & $\begin{array}{l}\text { Assess preferences for interacting and communicating } \\
\text { with team members }\end{array}$ & Identify personal characteristics & \multirow{3}{*}{$\begin{array}{l}\text { Team } \\
\text { functioning }\end{array}$} \\
\hline & b) & $\begin{array}{l}\text { Develop awareness and understanding of patterns of } \\
\text { preferences for each team member }\end{array}$ & Identify personal characteristics & \\
\hline & c) & $\begin{array}{l}\text { Communicate with team members based on identified } \\
\text { preferences }\end{array}$ & $\begin{array}{c}\text { Communicate/respect personal } \\
\text { characteristics }\end{array}$ & \\
\hline \multicolumn{5}{|c|}{ Emerged from Sport Psychology } \\
\hline \multirow{4}{*}{$\begin{array}{l}\text { 4. Framework for } \\
\text { examining the } \\
\text { correlates of } \\
\text { cohesion [14] }\end{array}$} & a) & $\begin{array}{l}\text { Identify contractual responsibilities/obligations (e.g., } \\
\text { eligibility rules) and organizational orientation (e.g., } \\
\text { age limitations; environmental factors) }\end{array}$ & Identify/respect context & \multirow{4}{*}{$\begin{array}{l}\text { Cohesion } \\
\text { Performance } \\
\text { Satisfaction }\end{array}$} \\
\hline & b) & $\begin{array}{l}\text { Identify individual team members' } \\
\text { orientation/motivation for being part of the team, } \\
\text { address individual differences, and nurture member } \\
\text { satisfaction (personal factors) }\end{array}$ & Identify/respect personal characteristics & \\
\hline & c) & $\begin{array}{l}\text { Identify necessary coach leadership behaviour and } \\
\text { style, and establish coach-athlete relationships } \\
\text { (leadership factors) }\end{array}$ & $\begin{array}{l}\text { Establish relationships } \\
\text { Establish leaders }\end{array}$ & \\
\hline & d) & $\begin{array}{l}\text { Identify group orientation, motives, and norms (team } \\
\text { factors) }\end{array}$ & $\begin{array}{l}\text { Identify team characteristics } \\
\text { Establish norms } \\
\end{array}$ & \\
\hline \multirow{4}{*}{$\begin{array}{l}\text { 5. Conceptual model } \\
\text { of cohesion [41] }\end{array}$} & a) & $\begin{array}{l}\text { Converge team members toward task achievement } \\
\text { (GI-T) }\end{array}$ & Converge members' attention on tasks & \multirow{4}{*}{ Cohesion } \\
\hline & b) & $\begin{array}{l}\text { Establish relationships to connect team members } \\
\text { (GI-S) }\end{array}$ & Establish relationships & \\
\hline & c) & $\begin{array}{l}\text { Identify each member's contributions to/satisfaction } \\
\text { with task achievement (ATG-T) }\end{array}$ & Establish roles & \\
\hline & d) & Establish friendships within the team (ATG-S) & Establish relationships & \\
\hline \multirow{3}{*}{$\begin{array}{l}\text { 6. Conceptual } \\
\text { framework of team } \\
\text { building }[9,11,49]\end{array}$} & a) & $\begin{array}{llll}\begin{array}{l}\text { Highlight distinctive } \\
\text { (environmental factors) }\end{array} & \text { group } & \text { characteristics } \\
\end{array}$ & Identify team characteristics & \multirow{3}{*}{ Cohesion } \\
\hline & b) & $\begin{array}{l}\text { Clarify and accept roles/positions, conform to norms, } \\
\text { and develop leadership (group structure factors) }\end{array}$ & $\begin{array}{l}\text { Establish/fulfill roles and norms } \\
\text { Establish leaders }\end{array}$ & \\
\hline & & $\begin{array}{l}\text { Set team goals, make sacrifices, cooperate, and } \\
\text { communicate/interact (group process factors) }\end{array}$ & $\begin{array}{c}\text { Set goals } \\
\text { Cooperate } \\
\text { Communicate } \\
\end{array}$ & \\
\hline
\end{tabular}


Table 1. Summary of processes and outcomes targeted in theoretical/conceptual frameworks of team processes in sport (continued)

\begin{tabular}{|c|c|c|c|c|}
\hline Framework & & Specific Team Processes & Broader Team Processes & Outcomes \\
\hline \multirow{3}{*}{$\begin{array}{l}\text { 7. Social-cognitive } \\
\text { framework of team } \\
\text { coordination and } \\
\text { communication in } \\
\text { sport [32] }\end{array}$} & a) & $\begin{array}{l}\text { Set goals, plan to achieve tasks, allocate roles and } \\
\text { responsibilities (pre-process coordination) }\end{array}$ & $\begin{array}{c}\text { Set goals } \\
\text { Plan tasks } \\
\text { Establish roles }\end{array}$ & \multirow{3}{*}{ Coordination } \\
\hline & b) & Communicate and adapt (in-process coordination) & $\begin{array}{c}\text { Communicate } \\
\text { Adapt to tasks and context }\end{array}$ & \\
\hline & c) & $\begin{array}{l}\begin{array}{l}\text { Communicate } \\
\text { coordination) }\end{array} \\
\end{array}$ & $\begin{array}{c}\text { Communicate } \\
\text { Evaluate tasks and context }\end{array}$ & \\
\hline
\end{tabular}

Table 2. Summary of general themes targeted in theoretical/conceptual frameworks of team processes in sport

\begin{tabular}{|c|c|c|c|c|c|c|c|c|c|c|c|}
\hline & Task & Context & Relationships & Roles/norms & $\begin{array}{c}\text { Personal } \\
\text { characteristics }\end{array}$ & $\begin{array}{c}\text { Team } \\
\text { characteristics }\end{array}$ & Goals & Communication & $\begin{array}{l}\text { Cooperation/ } \\
\text { coordination }\end{array}$ & Leadership & Total \\
\hline $\begin{array}{l}\text { 1. Theory of } \\
\text { group } \\
\text { development } \\
{[22,24]}\end{array}$ & $\mathrm{X}$ & $\mathrm{X}$ & $\mathrm{X}$ & $\mathrm{X}$ & $\mathrm{X}$ & $\mathrm{X}$ & & $\mathrm{X}$ & & & 7 \\
\hline $\begin{array}{l}2 . \text { Theory of } \\
\text { productivity [12] }\end{array}$ & & & & $\mathrm{X}$ & $\mathrm{X}$ & $\mathrm{X}$ & & & $\mathrm{X}$ & & 4 \\
\hline $\begin{array}{l}3 . \\
\text { Personality-based } \\
\text { preference } \\
\text { framework for } \\
\text { team } \\
\text { communication } \\
{[36]}\end{array}$ & & & & & $\mathrm{X}$ & & & $\mathrm{X}$ & & & 2 \\
\hline $\begin{array}{l}\text { 4. Framework for } \\
\text { examining the } \\
\text { correlates of } \\
\text { cohesion }[14]\end{array}$ & & $\mathrm{X}$ & $\mathrm{X}$ & $\mathrm{X}$ & $\mathrm{X}$ & $X$ & & & & $\mathrm{X}$ & 6 \\
\hline $\begin{array}{l}\text { 5. Conceptual } \\
\text { model of } \\
\text { cohesion [41] }\end{array}$ & $\mathrm{X}$ & & $\mathrm{X}$ & $\mathrm{X}$ & & & & & & & 3 \\
\hline $\begin{array}{l}\text { 6. Conceptual } \\
\text { framework of } \\
\text { team building } \\
{[9,11,49]}\end{array}$ & & & & $X$ & & $X$ & $X$ & $\mathrm{X}$ & $\mathrm{X}$ & $\mathrm{X}$ & 6 \\
\hline $\begin{array}{l}7 . \\
\text { Social-cognitive } \\
\text { framework of } \\
\text { team } \\
\text { coordination and } \\
\text { communication } \\
\text { in sport [32] }\end{array}$ & $\mathrm{X}$ & $\mathrm{X}$ & & $\mathrm{X}$ & & & $\mathrm{X}$ & $\mathrm{X}$ & & & 5 \\
\hline Total & 3 & 3 & 3 & 6 & 4 & 4 & 2 & 4 & 2 & 2 & \\
\hline
\end{tabular}

Despite its use in past research, limitations of Steiner's [12] theory must be addressed. First, it is difficult to determine the relationship between resources (i.e., individual psychosocial attributes and ability) and group effectiveness given that individuals have varying skills and personalities [12]. An additional limitation of Steiner's [12] theory is that it cannot account for when groups actually exceed their potential. As stated by Forsyth [26], "when people work in groups, they sometimes gain new solutions, energy, and insights into old problems that they would never have achieved as individuals" (p. 305). Thus, Forsyth [26] proposed that actual productivity equals potential productivity minus losses owing to faulty processes plus gains due to good processes, a phenomenon that cannot be explained using Steiner's [12] theory. The view that groups can exceed their potential is in line with the aim of team building interventions, which involve "blending the talents and strengths of individuals into a force that becomes greater than the sum of its parts" [21, p. 1].

Despite the aforementioned limitations, Steiner's [12] theory has practical implications for both group selection and maintenance. First, when forming a group, it is important that practitioners be mindful of the resources available within the group, such as the physical and/or cognitive ability of members, as well as the group size. Practitioners should then consider the following questions: (a) Based on the demands of the tasks, are these resources sufficient or are additional ones required? (b) What is the optimal group size that will allow members to effectively work together and achieve coordination? One may think that it is better to select more athletes in order to have the greatest potential resources (e.g., additional players from which to choose in case of injury, scheduling conflicts), however, Steiner's [12] theory suggests that this may do more damage than good from a 
coordination perspective. After team selection, practitioners should then be aware of strategies that can be used to promote effective team processes, and therefore minimize process losses. For example, process losses due to decreased motivation may be reduced by clarifying tasks and each member's role in accomplishing them so that each person feels like he or she is making a valuable contribution to the group. Losses may also be minimized by evaluating individual outputs so that each member is held accountable for his or her performances. For instance, a basketball coach could have an assistant track the statistics of a few players each game (e.g., shooting and freethrow percentages, turnovers, fouls) and discuss those statistics with the athletes after the game. From a coordination perspective, losses may be reduced by facilitating the development of shared knowledge via team post-game debriefs. For example, by reviewing videos of in-game coordination breakdowns with the whole team, practitioners could discuss with team members how to work more effectively together in similar future situations [35].

\subsubsection{Beauchamp, Maclachlan, and Lothian's [36] Personality-Based Preference Framework for Team Communication}

A third framework that has been used in sport psychology research is that of Beauchamp and colleagues [36]. Integrating Jung's [37] theory of personality types, these scholars proposed a personality-based preference framework for team communication that is unique in that it focuses on awareness and preferences for communication and interaction, which are not systematically addressed in any of the other frameworks included in this review. Within this framework, we identified two broader team processes (i.e., identify personal characteristics; communicate/respect personal characteristics) and the main outcome of team functioning (see Table 1).

Jung [37] suggested that people's personality emerges in the form of set preferences about the way they view the world. These differences stem from four functions (i.e., thinking, feeling, sensing, and intuition), and two attitudes (i.e., extraversion and introversion), which give rise to eight cognitive and behavioural preferences (e.g., extraverted thinking, introverted thinking, etc.). Based on the framework, in order to optimize team functioning, team members must assess preferences for interaction and communication with team members, develop an awareness and understanding of patterns of preferences of team members, and communicate with team members based on the identified preferences. According to Beauchamp and colleagues [36], by becoming more aware of behavioural preferences, team members may gain insight into how they like to: "(a) communicate and be communicated with..., (b) interact with teammates in both practice and social situations..., (c) resolve interpersonal conflicts..., and (d) deal with stressful situations" (p. 210-211). Assessment can be carried out using recognized instruments such as the Myers-Briggs Type Indicator (MBTI) and the Insights Discovery Evaluator (IDE) [38].

Beauchamp, Jackson, and colleagues [38] argued that it would be pointless to try and enhance or stifle the personality characteristics of team sport athletes. Instead, the emphasis should be on developing an awareness of the self and others. Beauchamp, Lothian, and Timson [39] conducted a team building intervention using the personality-based preference framework for team communication, which yielded promising results as it led to increased intra-group trust and cohesion, as well as improved group functioning. Moreover, implicit support for the framework is evident when examining recent team building interventions that have focused on increasing individual and collective awareness [2] and promoting mutual sharing and understanding $[3,19]$.

Merits notwithstanding, Beauchamp and colleagues' [36] framework is based on personality types and personality research in sport has been subject to a number of criticisms (e.g., role of the environment and its impact on behaviour is neglected). That said, the authors did emphasize that personality-based preferences were considered to be the result of both dispositional and situational factors. While personality tests are used in the assessment of preferences, the authors stressed that the purpose of this assessment is not to predict athletic success but rather to provide team members with a tool for increasing awareness.

Limitations aside, Beauchamp and colleagues' [36] framework highlights the importance of considering individuals' preferences for communication within the context of a team. Even in the absence of quantitative measures, practitioners can ask team members key questions in order to facilitate the development of a better understanding of themselves and their teammates. Sample questions might include: (a) When you make a mistake, what do you typically think and feel? (b) What can your teammates say or do to help you bounce back after mistakes? (c) What can you say or do to your teammates to help them reset after mistakes? A focus should be placed on not only each individual's preferences for communication, but also where each individual's preferences fit into the team as a whole. Once team members have a greater understanding "of what makes others... 'tick', this understanding can be used as a framework to help individuals communicate and interact more effectively within team situations" [38, p. 35]. For example, if team members understand that when a certain teammate commits an error, she gets really frustrated and angry with herself and needs a moment to calm down, they are then able to support her by giving her a minute of space before regrouping to talk about the next play.

\subsection{Frameworks from Sport Psychology}

\subsubsection{Carron's [14] General Framework for Examining the Correlates of Cohesion}

Carron's [14] general framework for examining the correlates of cohesion was pioneering in the field of sport psychology given the lack of theoretical frameworks for the study of cohesion in sport. Although Carron does not address 
specific team processes, we inferred six broader processes (i.e., identify/respect the context; identify/respect personal characteristics; establish relationships; establish leaders; identify team characteristics; establish norms) and three outcomes (i.e., cohesion, performance, satisfaction) based on the factors contributing to cohesion and performance he proposed (see Table 1). The framework is based on a hierarchy of four antecedents: (a) environmental factors (i.e., identify contractual responsibilities/obligations and organizational orientation); (b) personal factors (i.e., identify individual members' orientation/motivation, address individual differences, and nurture member satisfaction); (c) leadership factors (i.e., identify necessary leadership behaviour and style, and establish coach-athlete relationships); and (d) team factors (i.e., identify group orientation, motives, and norms), which are influenced by the other aforementioned factors. All four factors impact the throughput (i.e., type and level of cohesion present), with team factors exerting the most significant and direct impact. In turn, the type and level of cohesion influence individual (e.g., satisfaction) and group (e.g., performance) outcomes [14].

Of importance, Carron's [14] framework provided scholars with both a reference point for subsequent research and a means for making sense of incongruous findings. This resulted in an evolving conceptualization of cohesion in sport. For example, in the early version of Carron's [14] framework, only unidirectional relationships were depicted and moderating factors were ranked in order of importance. However, the model was later adapted in response to budding research in order to highlight the bidirectional nature of the antecedent-cohesion relationships [40] and the interdependent nature of the antecedents [9]. Carron's framework inspired extensive research on antecedent-cohesion and cohesion-outcome relationships in sport $[9,13]$.

Unfortunately, Carron's [14] framework does not specifically address the mechanisms (i.e., team processes) by which these relationships exist and develop. We inferred some processes based on the four factors presented in the model and the actions required to develop and/or maintain each one. The framework was initially developed to "help investigators systematically organize the research pertaining to cohesion" [28, p. 226], yet over the years, this purpose appeared to be misconstrued. As Carron and colleagues [9] stated in an author's note, "it was never intended to be a definitive view of the elements that cause cohesion and/or result from cohesion - although it was interpreted that way by a number of authors" (p. 242). Consequently, although Carron's [14] framework for examining the correlates of cohesion provides a valuable means for organizing research on the topic, researchers must be cautious not to look at the subject using a narrow research lens.

Despite not addressing specific team processes, Carron's [14] framework can provide direction to practitioners working with teams. Specifically, the framework demonstrates that in order to foster cohesion, there must be a certain level of congruence between the situation, the individuals on the team, leadership, and the team as a whole [9]. Interventions must target all areas where there is potential for enhancement. For example, cohesion can be fostered among team members through increased physical and functional proximity [an environmental factor; 9], therefore rooming assignments (e.g., pair a veteran with a rookie), tasks (e.g., get the defensive squad to discuss tactics), or team social gatherings (e.g., plan an activity for a teammate's birthday) can be used to promote closeness and communication among team members. Similarly, because a participative style of decision-making [a leadership factor; 9] is associated with cohesion, practitioners can facilitate discussions wherein team members are involved in making decisions. For example, a team meeting could be scheduled early in the season wherein team members could brainstorm and vote on team objectives for the season, as well as create team norms by discussing and deciding upon acceptable standards for behavior (e.g., punctuality, respect, support).

\subsubsection{Carron, Widmeyer, and Brawley's [41] Conceptual Model of Group Cohesion}

After Carron [14] created the general framework for examining the correlates of cohesion, Carron and colleagues [16] recognized that there were still limitations in the literature regarding the definition and conceptualization of cohesion. As such, they proposed a conceptual model of cohesion to further expand the literature, from which three broader team processes (i.e., converge members' attention on task; establish relationships; establish roles) and one outcome (i.e., cohesion) were identified (see Table 1).

This framework is important and was included in this review as a complement to Carron's [14] framework because it indirectly alludes to team processes and suggests that every team member "develops and holds perceptions about his/her team that are related to the group as a totality and to the manner in which the group satisfies personal needs and objectives" [42, p. 119]. It is the strength of these perceptions that keeps groups together. These perceptions are categorized as group integration (GI), which refers to a member's perceptions of closeness within the group, and attraction to group (ATG), which describes a member's motivations and feelings that attract him or her to the group $[9,41]$. These perceptions have both a task (T) and social (S) foci, thus there are four manifestations of cohesion in sport teams [i.e., GI-T, GI-S, ATG-T, and ATG-S; 9]. Accordingly, specific team processes alluded to in the model include: (a) converge team members towards task achievement (GI-T), (b) establish relationships to connect with team members (GI-S), (c) identify each team member's contributions to/satisfaction with task achievement (ATG-T), and (d) establish friendships within the team (ATG-S).

This model has formed the basis for the most widely used cohesion assessment instrument (the Group Environment Questionnaire, GEQ) and is based on three assumptions: (a) cohesion can be measured through individual perceptions of group members; (b) cognitions regarding cohesion involve 
both the group and the individual (i.e., GI and ATG); and (c) there are both task and social dimensions of cohesion [28]. As is the case with Carron's [14] model, Carron and colleagues' [41] conceptual model of group cohesion did not include specific team processes, however, these were inferred based on the manifestations discussed (i.e., integrate group members, attract individual members to the group).

There are a number of advantages to Carron and colleagues' [41] conceptualization of cohesion and its resultant questionnaire. This marked the first time that there was "consistency in the construct-operational definition link" in sport cohesion research [13, p. 362]. Previously, sport researchers had borrowed definitions from other contexts and "rarely... attempted to clarify the construct before measuring it" [41, p. 246]. For example, this was reportedly the case for the Sport Cohesiveness Questionnaire [SCQ; 43] and the Multidimensional Sport Cohesion Instrument [MSCI; 44], which limited their psychometric properties and applicability to sport research $[13,45]$.

Despite the obvious merits of the conceptual model of group cohesion and its corresponding measurement instrument, there are limitations. For example, the model only considers perceptions of individual members and thus assumes that members of cohesive teams share beliefs about cohesion [17]. However, there exists limited evidence that the notion of shared beliefs is valid [46,47], which begs the question: What should be the unit of analysis in sport cohesion studies - the individual, the group, or both? Further research is needed in order to provide additional validation for the model both at the conceptual and measurement level.

Despite these limitations, Carron and colleagues [41] highlight the importance of team members' individual motivations and feelings towards the group, both in regards to task and social elements. Based on the definitions of the GI-T, GI-S, ATG-T and ATG-S subscales, it is evident that group dynamics interventions need to focus on four aspects: (a) making members feel like they are unified in the pursuit of their goals (GI-T), (b) creating a social environment wherein team members feel close and connected to one another (GI-S), (c) ensuring that each member feels that he or she makes a valuable contribution to goal achievement (ATG-T), and (d) helping members develop friendships so that they feel like they belong (ATG-S) [25,48]. Intervention strategies can then target these four aspects. For instance, to address the GI-T aspect, practitioners can involve individuals in team goal setting practices, thereby promoting a sense of engagement while working towards a personally meaningful and common goal. Practitioners can also encourage athletes to establish team norms and expectations, and hold them accountable for their actions through the use of monitoring or evaluative strategies. By doing so, athletes are able to recognize their own contribution, as well as that of each teammate, in their goal pursuit.

\subsubsection{Carron and Spink's $[9,11,49]$ Conceptual Framework of Team Building}

Carron and Spink's [49] conceptual framework of team building was included in this review given that it was the first one in sport and exercise psychology that explicitly addressed team processes relevant to enhancing cohesion and team functioning. With a focus on the process of team building, it is an applied framework with relevant implications for practitioners. Six broader team processes were identified in the framework (i.e., identify team characteristics; establish/fulfill roles and norms; establish leaders; set goals; cooperate; communicate) that contribute to the outcome of cohesion (see Table 1).

Team building is the process of "team enhancement or team improvement for both task and social purposes" [9, p. 327]. Carron and Spink [49] proposed a conceptual model of team building for use in exercise settings that has since received widespread use in the context of sport. The framework forms a foundation for implementing interventions and suggests that in order to achieve the desired output (i.e., task and social cohesion), three categories of group characteristics must be targeted: two input categories (i.e., group environment and group structure) and one throughput category (i.e., team processes). A specific inferred team process related to the group environment involves highlighting distinctive team characteristics, whereas processes targeting group structure include clarifying and accepting roles and positions, conforming to norms and developing leadership. Explicitly reported throughput team processes consist of setting goals, making sacrifices, cooperating, and communicating/ interacting $[9,11,49]$. Embedded within the model of team building is a four-stage indirect (i.e., via the coach and not the athletes) intervention process that involves an introductory stage, conceptual stage, practical stage, and intervention stage [11,49]. During the first three stages, a practitioner works with the coach to help him or her establish the team building intervention (e.g., practical strategies, techniques, procedures, protocols). The coach then delivers the intervention in the fourth stage.

Several scholars have recognized the contribution of Carron and Spink's [49] model as it provides researchers with a more systematic and scientific approach to team building interventions [18,50]. Moreover, the framework highlights something that is missing from Carron and colleagues' [41] conceptual model of group cohesion and Carron's [14] general framework for examining the correlates of cohesion, that is, specific team processes and strategies to enhance cohesion and performance [13]. The indirect approach to team building is also considered advantageous as it combines the practitioner's knowledge of the process with the coach's knowledge of the team [51]. However, this model's strong emphasis on the coach's commitment and involvement brings forth some limitations.

As noted by Eitington [52], in order to be able to create change, leaders must have a number of qualities such as excellent listening skills, an ability to give and receive constructive feedback, and a capacity to create an environment of support and openness. They must also have considerable time, patience, commitment, and knowledge [50]. Interestingly, coaches' ability and commitment to 
delivering team building interventions has been questionable in a number of studies showing little or no effect [e.g., 11,51]. This has led scholars to suggest that a team diagnosis or assessment stage should preface the introductory stage in Carron and Spink's [49] framework [13,18]. Moreover, the belief that coaches must facilitate team building interventions is not as prevalent in the literature and consequently, researchers conducting intervention-based research are promoting a direct service approach involving trained practitioners [e.g., 2,3,19,53]. Finally, an additional limitation of the framework stems not from the framework itself, but from the methodological approach used to examine or implement interventions. Specifically, despite that team building is a longitudinal process, most studies are relatively short-term (i.e., 13 weeks or less) [8], thus long-term studies are warranted.

Despite these limitations, Carron and Spink's [49] framework has valuable implications for practitioners due to its emphasis on team processes, such as communication/ interaction, cooperation, and goal setting [9,49]. Given the impact of the group environment and structure on these various team processes and subsequent level of cohesion, practitioners should intervene at each level of the model. For example, they can address both the team structure and team processes by involving team members in regular meetings to discuss team norms, individual roles/positions, and leadership. During this time, veteran group members can be empowered to assist incoming members in adjusting to the new group climate and encouraging them to work together. Similarly, the team environment can be addressed by promoting distinctiveness, for example, by encouraging team members to communicate and interact with one another to develop a team identity, motto, or cheer [9,11]. Prompting team members to wear the same attire when they travel, wear matching warm-up suits, or dye their hair the same color for the playoffs would also promote distinctiveness.

\subsubsection{Eccles and Tenenbaum's [32] Conceptual Framework of Coordination in Teams}

The last framework by Eccles and Tenenbaum [32] was included given its explicit focus on the team processes of coordination and communication in sport. Six broader team processes (i.e., set goals; plan tasks; establish roles; communicate; adapt to tasks and context; evaluate tasks and context) were found to contribute to the outcome of coordination (see Table 1). The premise is that teams require coordination in order to be effective, which relies on shared knowledge. Coordination is "the process of arranging team members' actions so that, when they are combined, they are in suitable relation for the most effective result" [35, p. 32]. Shared knowledge can be acquired via pre-process, in-process, and post-process coordination [32]. Pre-process coordination includes setting goals, planning to achieve tasks, and allocating roles and responsibilities. In-process coordination relies on communication and includes adaptation. Finally, post-process coordination also relies on communication and involves evaluation.

As noted by Ward and Eccles [54], previously, scholars interested in team communication focused on factors that influence it (e.g., age, sex, religion, language, and culture) and the effect of communication on team cohesion and conflict. Eccles and Tenenbaum [32] were the first to examine team communication in relation to team coordination and performance. Their framework fills a gap in the literature by examining how teams achieve coordination, and the communication necessary for coordination $[55,56]$.

Alas, the evaluation of Eccles and Tenenbaum's [32] framework has been limited due to the lack of measures of coordination and communication in sport. Still, researchers have used video and audio recordings of athletes' performances to examine team communication [56] and coordination [55]. While these studies go a long way in describing coordination, the challenge for researchers will be to develop explanatory measures that "allow performance differences...to be captured, and that can be subsequently explained by individual and/or team process measures" [54, p. 477].

Despite the absence of assessment methods, Eccles and Tenenbaum's [32] framework suggests key ways that practitioners can help team members effectively work together. Specifically, practitioners should implement strategies that facilitate the development of shared knowledge. For instance, Eccles and Tran [35] recommend a number of solutions, one of which is 'position switching', in order for individuals to increase their understanding of the actions executed by other team members, thus allowing them to adapt and better coordinate their actions. Additional strategies to enhance shared knowledge relate to the ways in which game or action plans are communicated. For example, the authors recommend that when communicating plans to team members, practitioners should cater to athletes' preferred learning styles, repeat information, provide handouts or a video of the plan for later review, and explain why the plan is important and how it will help achieve the desired outcomes [35].

In sum, Table 1 demonstrates the variety of specific team processes that were either explicitly reported in certain frameworks or inferred based on definitions and concepts provided in the literature. Our critical analysis led us to classify these specific team processes under anywhere from two to twelve broader team processes within each framework. For ease of comparison between frameworks, these broader team processes were then regrouped under the following ten general themes in Table 2: (a) tasks, (b) context, (c) relationships, (d) roles/norms, (e) personal characteristics, (f) team characteristics, (g) goals, (h) communication, (i) cooperation/coordination, and (j) leadership. Tables 1 and 2 show that the frameworks addressing the most general themes and broader team processes include Tuckman's $[22,24]$ group development framework [7 themes; 12 broader team processes], Carron's [14] framework for examining the correlates of cohesion [ 6 themes; 6 broader 
team processes], and Carron and colleagues' [9,11,49] conceptual framework of team building [ 6 themes; 6 broader team processes]. On the other hand, the frameworks addressing the least number of general themes and broader team processes consist of Beauchamp and colleagues' [36] personality-based preference framework for team communication [2 themes; 2 broader team processes] and Carron and colleagues' [41] conceptual model of cohesion [3 themes; 3 broader team processes]. Furthermore, out of the ten general themes, the theme pertaining to roles/norms was the most prevalent one as it was addressed in six out of the seven frameworks. Conversely, goals, cooperation/coordination, and leadership were the least prevalent general themes, only discussed in two of the seven frameworks.

\section{Discussion and Concluding Remarks}

The purpose of this study was to critically examine frameworks of team processes in sport. In particular, we sought to (a) identify theoretical/conceptual frameworks in the literature addressing one or more team processes relevant for sport, (b) identify the specific team processes directly or indirectly targeted in these frameworks along with outcomes, (c) determine broader team processes and general themes and compare them across frameworks, (d) evaluate the frameworks based on their strengths and limitations, (e) report or infer implications for practice, and (f) make recommendations for future research. Seven frameworks used to guide research and/or practice in sport were identified. While three of the frameworks were borrowed from general psychology, four stemmed from the sport psychology literature. After critically reviewing the seven frameworks, it is apparent that no one framework addresses all specific or broader team processes appearing to be relevant for team functioning and effectiveness. While some frameworks are more comprehensive $[14,22,49]$, others are quite limited $[36,41]$ in terms of the number of team processes and general themes targeted.

The general theme and corresponding team processes that were most often explicitly or implicitly addressed related to roles/norms. Roles/norms were featured in six of the seven frameworks. Specifically, roles were addressed in five of the seven frameworks, while norms were identified in two frameworks. Roles and norms were grouped together into one general theme as both focus on the specific behaviours required of team members to fulfill either a position [i.e., roles; 57] or team standards [i.e., norms; 58]. Both dictate how team members will function within the team.

Both roles and norms have been the focus of many studies, however, roles have been more emphasized [8]. Based on the broader team processes that were identified in the current study, several actions including establishing, fulfilling, and adapting were associated with roles. This is consistent with existing research suggesting that role clarity, role acceptance, and role performance are necessary to achieve cohesion and optimal performance [57]. Congruent with recommendations for practice, roles for each team member must be clearly defined and communicated early in the season [57]. In doing so, practitioners must ensure that each role is accepted and viewed as equally important and valuable to team goal achievement [57,58]. This is especially crucial in high performance sport where athletes do not always receive equal opportunities [e.g., playing time; 57]. Given the recommendation that team building interventions be "developed on the basis of a theoretical understanding or modeling of how things work" $[7,60$, p. 518], it is not surprising that roles have been one of the most often targeted team processes in sport-based interventions [8].

The general themes of personal and team characteristics were also highlighted in several of the frameworks $(\mathrm{N}=4$ each) included in the present review. Traditionally, personal and team characteristics have been addressed in the literature as factors impacting team cohesion [12,14,22,24]; seldom have they been integrated into processes that could be nurtured. For instance, similarities in team members' perceptions, anxiety, and social loafing have been described as personal characteristics associated with cohesion [9,59]. In the current study, only two frameworks [36,49] explicitly highlighted the actions or processes involved in optimizing personal or team characteristics. Specifically, Beauchamp and colleagues [36] targeted personal characteristics and noted that team members must assess their preferences for interacting and communicating with team members, understand patterns of preferences for each member, and communicate based on these preferences when attempting to enhance team functioning. Carron and colleagues [49] discussed team characteristics in their conceptual framework of team building, and highlighted the importance of identifying distinctive team attributes in order to enhance cohesion.

By considering the two aforementioned frameworks [36, 49] and the broader team processes related to personal and team characteristics that emerged from our analysis, it becomes clear that characteristics are not merely fixed attributes that teams have or do not have. Rather, practitioners can intervene by helping team members identify, challenge, communicate, and respect personal and team characteristics. Beauchamp, Jackson, and Lavallee [38] argued that when attempting to build optimally functioning teams, practitioners have two choices: to "select (or deselect) the appropriate personnel to fit the team's needs...[or] to train existing members to more effectively contribute to the team's objectives" [p. 34]. This supports the notion that characteristics can be nurtured by practitioners to achieve desired outcomes.

Another general theme that was commonly addressed in four of the seven frameworks was communication. Our analysis shows that communication is a team process involving both task and social aspects, although most frameworks address only one of these aspects, which is a limitation. Communication has been generally cited as a key team process in the cohesion and team building literature $[1,9,32,61]$. While it was a prevalent theme in the current 
study, it is surprising that it was not addressed in all seven frameworks given that it appears to underlie most of the broader team processes. For instance, one could argue that team members must communicate in order to identify and challenge team characteristics, establish relationships, establish roles and norms, and coordinate tasks. This notion was corroborated by Eys and colleagues [57] who stated that "effective communication is a pivotal aspect of effective intervention strategies" (p. 109). As such, practitioners should encourage effective communication while cultivating other team processes.

One of the general themes that was addressed in the least number of frameworks $(\mathrm{N}=2)$ pertained to goals. This was unexpected given the amount of research on goal-setting in general and the prevalence of this team process in team building intervention research $[7,60,62,63]$. Interestingly, goal setting has been the most targeted team building strategy in sport [8] and goal setting interventions have been shown to have the strongest effect size in a recent meta-analysis [7]. This suggests that although goal-setting was not integrated in many frameworks, practitioners should still be mindful of its importance when attempting to enhance team functioning. This finding also supports the argument that some frameworks may not be comprehensive enough to assist practitioners in their work with teams.

As evidenced in Table 1, cohesion was the most prevalent outcome addressed in the seven frameworks $(\mathrm{N}=4)$. This confirms what is advocated in the general sport psychology literature that cohesion is the most popular topic studied and/or targeted in relation to teams $[1,7,8]$. However, McEwen and Beauchamp [1] have suggested that "there is more to being an effective team than merely being a cohesive one" [p. 233], and that team cohesiveness is not synonymous with team effectiveness. In fact, athletes have identified that high levels of cohesion can actually hinder team performance [e.g., by creating communication difficulties; 64]. As noted by Bruner and colleagues, "the restricted focus on cohesion suggests that research conducted within the area of team building in sport is relatively narrow" [65, p. 37]. Consequently, McEwan and Beauchamp [1] advocated that applied researchers, and arguably practitioners, should focus on specific team processes (e.g., setting goals, communicating, monitoring performance, problem solving) that may contribute to enhanced team functioning.

Given that team processes have been linked to various positive outcomes in the literature, there is a need to facilitate knowledge transfer in order to help practitioners use empirical findings when working with teams. Our analysis enabled us to provide examples of applications for each theoretical or conceptual framework included in this study. However, this applied information was not forthcoming and it was limited in certain frameworks given the narrow focus of these frameworks. Also, there appears to be a disconnect between constructs presented in different publications of the same frameworks [e.g., goals were not included in earlier publications of Carron and colleagues' framework of team building but were so in later publications, see 9,11,49]. Researchers must thus invest more effort into providing concrete guidelines to not only help practitioners build effective teams in their practice, but also guide researchers attempting to use frameworks in intervention studies and report applicable findings. Further, additional research is required to advance more comprehensive "how to" frameworks that will visibly assist practitioners and researchers in optimizing essential team processes in sport.

It is noteworthy that frameworks can be developed using a 'top-down' (e.g., theory is developed based on a review of existing literature) or 'bottom-up' (i.e., theory is grounded in the experiences of the participants under study) approach. One conceptual framework that has been recently generated using a 'top-down' approach is that of McEwan and Beauchamp [1]. This multidimensional framework of teamwork in sport was predominantly drawn from the organizational psychology literature. Although it has yet to be tested and used in sport psychology research, it shows great promise given its emphasis on a variety of teamwork behaviours (i.e., team processes) that can be nurtured over time and across contexts. Some of these behaviours were not addressed in any of the seven frameworks included in this study (e.g., systems and performance monitoring, problem solving, support). While specific practical implications of this framework have not been provided at this point in the literature, various examples of inputs, team processes, and outcomes give insight into the future applicability of this framework to enhance team functioning and effectiveness in sport.

There is also value in considering 'bottom-up' approaches when developing evidenced-based frameworks. For example, it would appear to be important for scholars to immerse themselves 'in the field' to gather data directly from teams to get their perceptions of what they require from practitioners and leaders to develop and optimize team processes. This is of particular relevance given that all of the frameworks presented in this study appear to have been deductively developed based on literature reviews and/or a limited empirical database. For example, a grounded theory approach with which data are collected from participants who have experienced the processes, actions, or interactions under study [66], may help uncover team processes that were not explicitly or extensively addressed in the existing frameworks. This approach would also lend itself well to obtaining a more comprehensive account of a variety of team processes deemed necessary for optimal functioning in a particular context. More specific applied strategies linked to these team processes could be examined as well in order to provide concrete empirical data to guide practitioners. Congruent with a grounded theory approach, the data could ultimately lead to the development of a sound theory on the use and application of team processes that could inform practice as well as future research. It is our hope that this review will be a springboard for studies in this area. 


\section{REFERENCES}

[1] McEwan, D., \& Beauchamp, M. R. (2014). Teamwork in sport: A theoretical and integrative review. International Review of Sport and Exercise Psychology, 7, 229-250.

[2] Collins, J., \& Durand-Bush, N. (2010). Enhancing the cohesion and performance of an elite curling team through a self-regulation intervention. International Journal of Sports Science and Coaching, 5, 343-362.

[3] Dunn, J. G., \& Holt, N. L. (2004). A qualitative investigation of a personal-disclosure mutual-sharing team building activity. The Sport Psychologist, 18, 363-380.

[4] Goodger, K., Gorely, T., Lavallee, D., \& Harwood, C. (2007). Burnout in sport: A systematic review. The Sport Psychologist, 21, 127-151.

[5] Carron, A. V., Colman, M. M., Wheeler, W., \& Stevens, D. (2002). Cohesion and performance in sport: A meta analysis. Journal of Sport \& Exercise Psychology, 24, 168-188.

[6] Filho, E., Dobersek, U., Gershgoren, L., Becker, B., \& Tenenbaum, G. (2014). The cohesion-performance relationship in sport: A 10-year retrospective meta-analysis. Sport Sciences for Health, 10, 165-177.

[7] Martin, L. J., Carron, A. V., \& Burke, S. M. (2009). Team building interventions in sport: A meta-analysis. Sport \& Exercise Psychology Review, 5, 3-18.

[8] Rovio, E., Arvinen-Barrow, M., Weigand, D., Eskola, J., \& Lintunen, T. (2010). Team building in sport: A narrative review of the program effectiveness, current methods, and theoretical underpinnings. Athletic Insight, 2, 1-19.

[9] Carron, A. V., Hausenblas, H. A., \& Eys. M. A. (2005). Group dynamics in sport $\left(3^{\text {rd }}\right.$ ed.). Morgantown, WV: Fitness Information Technology.

[10] Beauchamp, M. R., \& Eys, M. A. (2008). Group dynamics in exercise and sport psychology: Contemporary themes. New York: Routledge.

[11] Prapavessis, H., Carron, A. V., \& Spink, K. S. (1996). Team building in sport. International Journal of Sport Psychology, $27,269-285$.

[12] Steiner, I. D. (1972). Group process and productivity. New York: Academic Press.

[13] Brawley, L. R. (1990). Group cohesion: Status, problems, and future directions. International Journal of Sport Psychology, $21,355-379$.

[14] Carron, A. V. (1982). Cohesiveness in sport groups: Interpretations and considerations. Journal of Sport Psychology, 4, 123-138.

[15] Mudrack, P. E. (1989). Group cohesiveness and productivity: A closer look. Human Relations, 42, 771-785.

[16] Carron, A. V., Brawley, L. R., \& Widmeyer, W. (1998). The measurement of cohesiveness in sport groups. In J. L. Duda (Ed.), Advancements in sport and exercise psychology measurement (pp. 213-226). Morgantown, WV: Fitness Information Technology.
[17] Paskevich, D. M., Estabrooks, P. A., Brawley, L. R., \& Carron, A. V. (2001). Group cohesion in sport and exercise. In R. N. Singer, H. A. Hausenblas, \& C. M., Janelle (Eds.), Handbook of sport psychology (pp.472-494). New York: Wiley.

[18] Loughead, T. M., \& Hardy, J. (2006). Team cohesion: From theory to research to team building. In S. Hanton \& S. D. Mellalieu (Eds.), Literature reviews in sport psychology (pp. 257-287). Hauppauge, NY: Nova Science Publishers.

[19] Pain, M. A., \& Harwood, C. (2009). Team building through mutual sharing and open discussion of team functioning. The Sport Psychologist, 23, 523-542.

[20] Marks, M. A., Mathieu, J. E., \& Zaccaro, S. J. (2001). A temporally based framework and taxonomy of team processes. The Academy of Management Review, 26, 356-376.

[21] Hardy, C. J., \& Crace, R. K. (1997). Foundations of team building: Introduction to the team building primer. Journal of Applied Sport Psychology, 9, 1-10.

[22] Tuckman, B. W. (1965). Developmental sequences in small groups. Psychological Bulletin, 63, 384-399.

[23] Carron, A. V., \& Spink, K. S. (1995). The group size-cohesion relationship in minimal groups. Small Group Research, 26, 86-105.

[24] Tuckman, B. W., \& Jensen, M. A. (1977). Stages of small group development revisited. Group and Organizational Studies, 2, 419-427.

[25] Weinberg, R. S., \& Gould, D. (2003). Foundations of sport and exercise psychology ( $3^{\text {rd }}$ ed.). Champaign, IL: Human Kinetics.

[26] Forsyth, D. R. (2010). Group dynamics ( $5^{\text {th }}$ ed.). Belmont, CA: Wadsworth, Cengage Learning.

[27] Holliday, B., Burton, D., Sun, G., Hammermeister, J., Naylor, S., \& Freigang, D. (2008). Building the better mental training mousetrap: Is periodization a more systematic approach to promoting performance excellence? Journal of Applied Sport Psychology, 20, 199-219.

[28] Carron, A. V., \& Brawley, L. R. (2008). Group dynamics in sport and physical activity. In T. S. Horn (Ed.), Advances in sport psychology ( $3^{\text {rd }}$ ed., pp. 213-238). Champaign, IL: Human Kinetics.

[29] Kravitz, D. A., \& Martin, B. (1986). Ringelmann rediscovered: The original article. Journal of Personality and Social Psychology, 5, 936-941.

[30] Ringelmann, M. (1913). Recherches sur les moteurs animés: Travail de l'homme [Research on animate sources of power: The work of man]. Annales de l'Institut National Agronomique, 2e série - tome XII, 1-40.

[31] Eccles, D. W. (2010). The coordination of labour in sports teams. International Review of Sport and Exercise Psychology, 3, 154-170.

[32] Eccles, D. W., \& Tenenbaum, G. (2004). Why an expert team is more than a team of experts: A cognitive conceptualization of team coordination and communication in sport. Journal of Sport and Exercise Psychology, 26, 542-560.

[33] Eccles, D. W., \& Johnson, M. B. (2009). Letting the social and cognitive merge: New concepts for an understanding of 
group functioning in sport. In S. D. Mellalieu \& S. Hanton (Eds.), Advances in applied sport psychology: A review (pp. 281-316). New York: Routledge.

[34] Widmeyer, W. N., Brawley, L. R., \& Carron, A. V. (1990). The effects of group size in sport. Journal of Sport and Exercise Psychology, 12, 177-190.

[35] Eccles, D. W., \& Tran, K. B. (2012). Getting them on the same page: Strategies for enhancing coordination and communication in sports teams. Journal of Sport Psychology in Action, 3, 30-40.

[36] Beauchamp, M. R., Maclachlan, A., \& Lothian, A. M. (2005). Communication within sport teams: Jungian preferences and group dynamics. The Sport Psychologist, 19, 203-220.

[37] Jung, C. G. (1971). The collected works of C. G. Jung (Vol. 6). Princeton, NJ: Princeton University Press.

[38] Beauchamp, M. R., Jackson, B., \& Lavallee, D. (2008). Personality processes and intra-group dynamics in sport teams. In M. R. Beauchamp \& M. A. Eys (Eds.), Group dynamics in exercise and sport psychology: Contemporary themes (pp. 25-42). New York: Routledge.

[39] Beauchamp, M. R., Lothian, J. M., \& Timson, S. E. (2008). A personality preference-based intervention with an elite co-acting sport team. Sport and Exercise Psychology Review, 4, 4-20.

[40] Carron, A. V., \& Hausenblas, H. A. (1998). Group dynamics in sport $\left(2^{\text {nd }}\right.$ ed.). Morgantown, WV: Fitness Information Technology.

[41] Carron, A. V., Widmeyer, N. W., \& Brawley, L. R. (1985). The development of an instrument to assess cohesion in sport teams: The Group Environment Questionnaire. Journal of Sport Psychology, 7, 244-266.

[42] Carron, A. V., Shapcott, K. M., \& Burke, S. M. (2008). Group cohesion in sport and exercise: Past, present and future. In M. R. Beauchamp \& M. A. Eys (Eds.), Group dynamics in exercise and sport psychology: Contemporary themes (pp. 117-139). New York: Routledge.

[43] Martens, R., Landers, D. M., \& Loy, J. W. (1972). Sport cohesiveness questionnaire. Washington, DC: AAHPERD Publications.

[44] Yukelson, D., Weinberg, R., \& Jackson, A. (1984). A multidimensional group cohesion instrument for intercollegiate basketball. Journal of Sport Psychology, 6, 103-117.

[45] Widmeyer, W. N., Brawley, L. R., \& Carron, A. V. (2002). Group dynamics in sport. In T. Horn (Ed.), Advances in Sport Psychology ( $2^{\text {nd }}$ ed., pp. 285-308). Champaign, IL: Human Kinetics.

[46] Carron, A. V., Brawley, L. R., Bray, S., Eys, M. A., Dorsch, K., Estabrooks, P.,...Terry, P. C. (2004). Using consensus as a criterion for groupness: Implications for the cohesion-group success relationship. Small Group Research, 35, 466-491.

[47] Carron, A. V., Brawley, L. R., Eys, M. A., Bray, S., Dorsch, K., Estabrooks, P.,...Terry, P. C. (2003). Do individual perceptions of group cohesion reflect shared beliefs? An empirical analysis. Small Group Research, 34, 469-496.

[48] Eys, M. A., Carron, A. V., Bray, S. R., \& Brawley, L. R. (2007). Item wording and internal consistency of a measure of cohesion: The Group Environment Questionnaire. Journal of Sport and Exercise Psychology, 29, 395-402.

[49] Carron, A. V., \& Spink, K. S. (1993). Team building in an exercise setting. The Sport Psychologist, 7, 8-18.

[50] Brawley, L. R., \& Paskevich, D. M. (1997). Conducting team building research in the context of sport and exercise. Journal of Applied Sport Psychology, 9, 11-40.

[51] Carron, A. V., Spink, K. S., \& Prapavessis, H. (1997). Team building and cohesiveness in the sport and exercise setting: Use of indirect interventions. Journal of Applied Sport Psychology, 9, 61-72.

[52] Eitington, J. E. (1989). The winning trainer ( $2^{\text {nd }}$ ed.). Houston, TX: Gulf Publishing Company.

[53] Voight, M., \& Callaghan, J. (2001). Team building intervention program: Application and evaluation with two University soccer teams. Journal of Sport Behavior, 24, 420-431.

[54] Ward, P., \& Eccles, D. W. (2006). A commentary on "team cognition and expert teams: Emerging insights into performance for exceptional teams". International Journal of Sport and Exercise Psychology, 4, 463-483.

[55] Bourbousson, J., Poizat, G., Saury, J., \& Seve, C. (2010). Team coordination in basketball: Description of the cognitive connections among teammates. Journal of Applied Sport Psychology, 22, 150-166.

[56] Lausic, D., Tenenbaum, G., Eccles, D. W., Jeong, A., \& Johnson, T. (2009). Intra-team communication and performance in doubles tennis. Research Quarterly for Exercise and Sport, 80, 281-290.

[57] Eys, M. A., Schinke, R. J., \& Jeffery, S. M. (2007). Role perceptions in sport groups. In M. R. Beauchamp \& M. A. Eys (Eds.), Group dynamics in exercise and sport psychology: Contemporary themes (pp. 99-115). New York: Routledge.

[58] Høigaard, R., Säfvenbom, R., \& Tønnessen, F. E. (2006). The relationship between group cohesion, group norms, and perceived social loafing in soccer teams. Small Group Research, 37, 217-232.

[59] Eys, M. A., Burke, S. M., Carron, A. V., \& Dennis, P. W. (2010). The sport team as an effective group. In J. M. Williams (Ed.), Applied sport psychology: Personal growth to peak performance (pp. 132-148). New York: McGraw Hill.

[60] Evans, M. B., Eys, M. A., Brunner, M. W., \& Kleinert, J. (2014). Building cohesive groups. In A. G. Papaioannou \& D. Hackfort (Eds.), Routledge companion to sport and exercise psychology: Global perspectives and fundamental concepts (pp. 513-528). New York: Routledge.

[61] Yukelson, D. (2010). Communicating effectively. The sport team as an effective group. In J. M. Williams (Ed.), Applied sport psychology: Personal growth to peak performance (pp. 149-165). New York: McGraw Hill.

[62] Kyllo, L. B., \& Landers, D. M. (1995). Goal setting in sport and exercise: A research synthesis to resolve controversy. Journal of Sport \& Exercise Psychology, 17, 117-137.

[63] Gould, D. (2010). Goal setting for peak performance. In J. M. Williams (Ed.), Applied sport psychology: Personal growth to peak performance (pp. 201-220). New York: McGraw Hill. 
[64] Hardy, J., Eys, M., \& Carron, A. (2005). Exploring the potential disadvantages of high cohesion in sports teams. Small Group Research, 36, 166-187.

[65] Bruner, M. W., Eys, M. A., Beauchamp, M. R., \& Côté, J. (2013). Examining the origins of team building in sport: A citation network and genealogical approach. Group Dynamics: Theory, Research, and Practice, 17, 30-42.

[66] Creswell, J. W. (2007). Qualitative inquiry and research design: Choosing among five approaches ( $2^{\text {nd }}$ ed.). Thousand Oaks, CA: SAGE Publications. 